\title{
Two Rainfall-Characteristic Indices Proposed as Suitable for Agricultural Planning in Puerto Rico'
}

\author{
Modesto Capiel and Mariano Antoni ${ }^{2}$
}

\section{INTRODUCTION}

There is limited quantitative information pertaining to rainfall distribution in Puerto Rico aside from published summarized records of the 10and 30-year monthly and annual rainfall data. Rainfall statistics are summarized by year and decade $(6,8)$. Daily and monthly values of rainfall, temperature and other weather data appear more currently (5).

The maximum expected rainfall for various short durations and return periods also have been published (7). The isopluvial maps presented for 10-, 25-, and 50-year return periods indicate that the maximum expected rainfall for 24 hours is 8,10 , and 11 inches for Caguas, and 9, 11, and 12 inches for Fajardo, respectively.

Meteorological drought incidence for six climatological divisions in Puerto Rico has been analysed by Calvesbert (2). In reviewing and applying the Palmer's Drought Index, Calvesbert concluded that the method furnishes a deeper insight of the climatology of meteorological drought in Puerto Rico and a means for measuring one of the Island's most severe weather problems aside from that of tropical storms. On the basis of the evaluation of the index it was found that all regions experienced severe drought conditions with greatest intensity during 1948 and 1964. The year 1967 was not covered by the study. There is no published data, however, describing the distribution of rainfall and its characteristics based on long periods and in terms significant to agriculture.

Pico (4) rather briefly mentions the nature of, and factors affecting rainfall in Puerto Rico. Howarth, according to Picó (4), divided the Island into 11 regions, basing his classification on the general character of rainfall distribution. Fajardo is classified in Region IV-Subhumid East in which annual rainfall ranges between 40 and 70 inches $(1,000-1,800 \mathrm{~mm}$.,

1 Manuscript submitted to Editorial Board April 20, 1972.

2 Agricultural Climatologist and Assistant Statistician in Charge, Agricultural Engineering Department and Statistics Section, respectively, Agricultural Experiment Station, Mayagüez Campus, University of Puerto Rico, Río Piedras, P. R. The authors are grateful to Prof. D. Clay MeDowell, Director, Institute of Tropical Meteorology, University of Puerto Rico, Río Piedras, and to Mr. Robert J. Calvesbert, Commonweal th Climatologist, E.S.S.A., San Juan, P.R. for suggestions and criticism of this paper. 
approximately), while Caguas is in Region XI-Humid Mountains in the East, with rainfall ranging between 50 and 80 inches $(1,300-2,000 \mathrm{~mm}$., approximately). Pico indicates that the orographic rainfall in this region appears non-significant because it lies in lower areas, and leeward with respect to Sierra de Luquillo. Appreciable shower activity is experienced in the rugged Caguas Valley however, especially with SE winds.

It is highly desirable to examine Puerto Rican rainfall data from the viewpoint of distribution and seasonal deficiency. Only by such investigation can sound planning of water resources be conducted in terms of water storage potential in certain areas and in terms of establishing supplemental irrigation priorities. Such information can lead to more effective flood control measures. The future development of this natural resource in Puerto Rico must be taken more seriously. The mountainous topography of the Island is generally considered to be a liability to progress because few realize how much easier it is to develop water resources under the existing topography than under rather flat land conditions.

Once a complex of hydraulic works islandwide is designed and constructed rural life will be more attractive by generating more jobs, by adding greater perspectives to agricultural diversification, and by furnishing better recreational facilities for rural areas.

This paper presents data useful in determining the extent to which rainfall may be regarded as an asset or liability,-one way or the otherduring periods of drought and intensive rainfall.

Bogart et al. (1) report that, of the 69 inches of average annual rainfall in Puerto Rico, 42 inches go to evapotranspiration, 23 to stream runoff, and 4 to ground water discharge to the sea. Of the 23 inches of stream runoff, or 4.1 million acre-feet, termed the average annual controllable supply, the total consumptive use in 1960 was 580,000 acre-feet; only 14 percent. The greater part of the Island's water thus remains for future development. About 430,000 acre-feet, 75 percent of the total consumptive use, went into irrigation. Thus, if the 14 percent of the stream runoff is simply doubled, over 800,000 acre-feet of water could be diverted to irrigation.

This quantity of available water could mean much to agricultural diversification as well as to rural life in general.

The results of this study indicate the magnitude of wet and dry periods in terms of accumulated rainfall for durations that may influence crop management decisions, such as irrigation requirements, pesticide programs, land preparation, planting and harvest dates. It further provides a mechanism to further deliniate trends or character in rainfall distribution.

Finally, a rainfall deficiency index was developed for establishing supplemental irrigation priorities, which can be used as a guide for selecting optimum enterprises for given regions. 


\section{METHOD OF ANALYSIS}

The daily rainfall data for Caguas and Fajardo, including 70- and 60year records, respectively, were organized to determine the least rainfall in 60,120 , and 180 consecutive days of the year, as well as the maximum rainfall in 30 and 90 consecutive days of the year. November 16 was taken as the first day of the yearly rainfall cycle considering that the reduction in rainfall frequently begins early in December. Minimum and maximum values obtained from these calculations were used to develop equations that would give a relative appraisal of rainfall distribution of the particular year.

The third moment coefficient of skewness $\left(a_{3}\right)$, as defined by Mode (2), was determined for each of the maximum rainfall parameters and compared to the annual rainfall coefficient. This coefficient of skewness gives a measure of the degree of asymmetry with respect to the mean, as well as the amount of dispersion above or below the mean.

The final step in the rainfall analysis was the development of a Rainfall Deficiency Index, based on the rainfall deficiency and its distribution, as reflected by the accumulated amounts of rainfall by 10-day increments.

\section{RESULTS AND DISCUSSION}

\section{RAINFALL CHARACTERISTICS}

The yearly least rainfall in 60,120 , and 180 consecutive days at Caguas and Fajardo are shown in figures 1 and 2, respectively. Both areas exhibit a similar spread and a rather decreasing trend of the data pertaining to 60 and 120 days least rainfall. While the least rainfall in 180 days at Caguas exhibits a significant decreasing trend, that of Fajardo exhibits considerable spread with little or no apparent trend. The superimposed broken lines drawn to indicate the trend of the data have been based on the regression of 10-year mean values of the least rainfall periods on the decade number; 1 to 7 for Caguas (1899-1968) and 1 to 6 for Fajardo (1909-1968). Tables 1 and 2 indicate the regression and correlation coefficients ( $\beta$ and $r$ ) connected with the broken lines and the mean values and standard deviations by decades for the Caguas and Fajardo data, respectively. Tables 1 and 2 indicate that the Caguas and Fajardo data are similar in trend and spread of the least rainfall in 60 and 120 days, their mean annual rainfall, and also their average by decades (see $\beta$ and $r$ ).

Figures 3 and 4 show the corresponding graphs of maximum rainfall in 30 and 90 days at Caguas and Fajardo, respectively. The maximum rainfall in 30 days at Caguas exhibits the most apparent decreasing trend. This is confirmed by the values of $\beta$ and $r$ in tables 1 and 2 . The time-course of the maximum rainfall in 90 days (averaged by decades) also suggests a de- 


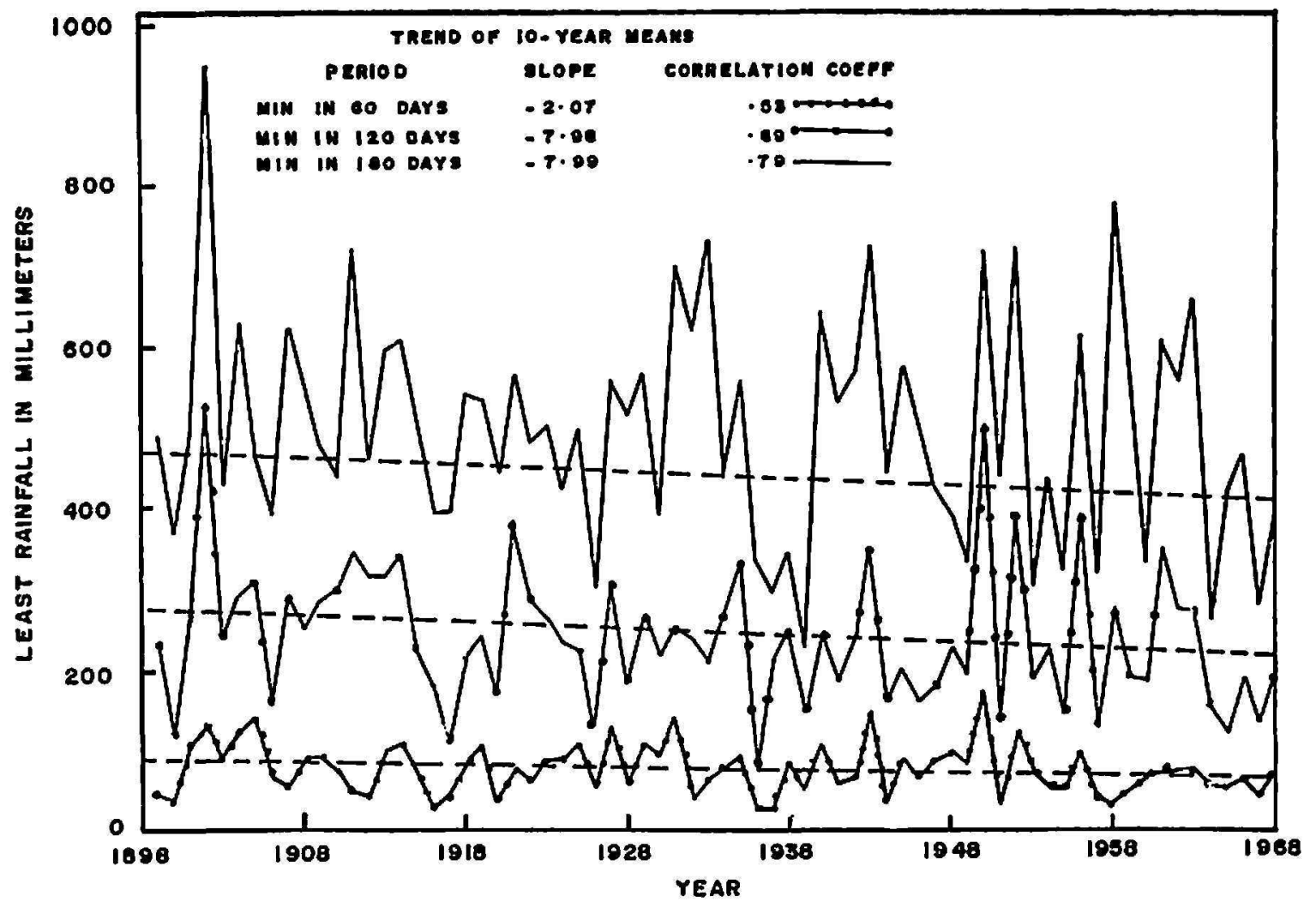

FIG. 1.-Least rainfall in 60-, 120-, and 180-day periods at Caguas during 70 years of daily records. The trend of the least rainfall with time, calculated from 10-year means of the indicated periods, is shown as to slope and correlation coefficient of the data superimposed over each time-course curve.

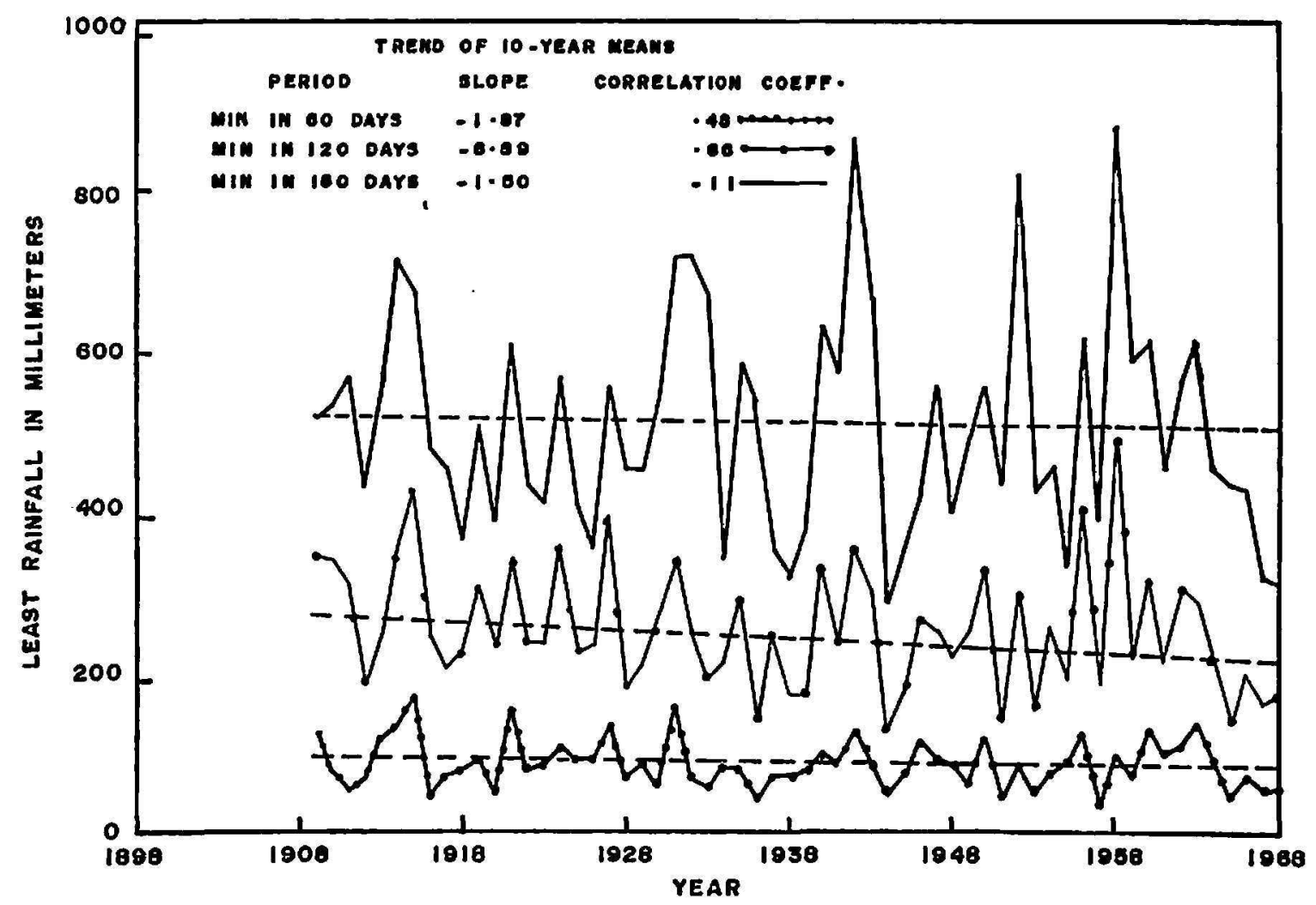

Fra. 2.-Least rainfall in 60-, 120-, and 180-day periods at Fajardo during 60 years of daily records. The trend of the least rainfall with time, calculated from 10 -year means of the indicated periods, is shown as to slope and correlation coefficient of the data superimposed over each time-course trend. 
TABLE 1.-Mean and standard deviation of the least and maximum rainfall in Caguas for various time intervals of the year, calculated by decades along a 70-year period (1899-1968). The regression coefficient $(\beta)$ and the correlation coefficient $(r)$, obtained when relating the amount of rainfall to the decade number $(1107)$, are presented as a measure of the trend in either the least or maximum rainfall periods

\begin{tabular}{|c|c|c|c|c|c|c|c|}
\hline \multirow{2}{*}{$\begin{array}{l}\text { Period and } \\
\text { decade number }\end{array}$} & \multirow{2}{*}{ Measure } & \multicolumn{3}{|c|}{ Least rainfall in- } & \multicolumn{2}{|c|}{ Maximum rainfall in- } & \multirow{2}{*}{$\begin{array}{l}\text { Mcan, } \\
\text { annual }\end{array}$} \\
\hline & & 60 days & 120 days & 180 days & 30 days & 90 days & \\
\hline & & $M m$. & $M m$. & $M m$. & $M m$. & $\Delta I m$. & $\mathbf{M m}$. \\
\hline 1899-1908 & mean & 87.9 & 268.7 & 537.2 & 395.2 & 746.3 & 1757.7 \\
\hline (1) & s.d. & 37.1 & 110.2 & 170.9 & 121.4 & 197.4 & 352.5 \\
\hline $1909-1918$ & mean & 67.8 & 261.1 & 509.3 & 328.7 & 630.9 & 1458.7 \\
\hline$(2)$ & s.d. & 29.5 & 77.5 & 105.7 & 55.4 & 105.7 & 239.5 \\
\hline $1919-1928$ & mean & 80.3 & 240.3 & 480.8 & 353.8 & 646.2 & 1563.6 \\
\hline (3) & s.d. & 26.7 & 74.7 & 96.5 & 154.7 & 170.7 & 269.5 \\
\hline $1929-1938$ & mean & 74.9 & 232.4 & 495.0 & 336.8 & 668.5 & 1624.6 \\
\hline (4) & s.d. & 36.5 & 65.5 & 157.0 & 67.1 & 170.9 & 352.3 \\
\hline $1939-1948$ & mean & 81.0 & 207.8 & 485.6 & 349.8 & 698.5 & 1597.7 \\
\hline (5) & s.d. & 33.5 & 58.7 & 152.4 & 113.3 & 253.5 & 368.8 \\
\hline 1949-1958 & mean & 76.2 & 257.3 & 495.3 & 311.7 & 696.7 & 1616.2 \\
\hline (6) & s.d. & 44.7 & 129.8 & 189.2 & 61.5 & 150.9 & 295.9 \\
\hline $1959-1968$ & mean & 62.7 & 207.6 & 470.4 & 293.1 & 587.9 & 1439.7 \\
\hline (7) & s.d. & 10.9 & 69.8 & 167.6 & 113.3 & 169.2 & 312.7 \\
\hline Mean rainfall & $\boldsymbol{\beta}$ & -2.07 & -7.98 & -7.99 & -12.30 & -10.40 & -22.8 \\
\hline $\begin{array}{c}\text { vs. } \\
\text { decade num. }\end{array}$ & & 0.53 & 0.69 & $0.79^{*}$ & $0.81 *$ & 0.43 & 0.44 \\
\hline 70-year & mean & 75.8 & 239.3 & 496.2 & 338.3 & 667.8 & 1579.9 \\
\hline (1899-1968) & s.d. & 32.5 & 86.4 & 147.1 & 103.6 & 180.3 & 318.3 \\
\hline
\end{tabular}

* Significant at the 5-percent level.

creasing trend for Caguas but is not significant (see $\beta$ and $r$ on table 1 ). That of Fajardo has a skew distribution with no apparent trend with time.

Interestingly, years ending in 6 or 7 generally are among those with most deficient rainfall in 120 days and/or 180 days. Years ending in 1 or 2 generally are among those with the least deficient rainfall in the drier part of the year. This apparently cyclic occurrence of a particularly dry and a "wet" ${ }^{3}$ year within each decade is especially evident in the Caguas area. It is generally recognized that a dry period in Puerto Rico extends from 3 to 4 months, especially in the subhumid areas, thus the calculated least rainfall in 120 days should give a good measure of the magnitude of the drought; at least relative to other years.

"The word "wet" as used here has been enclosed in quotation marks to indicate that it refers to relative and not to absolute rainfall conditions. 
Table 3 presents the mean values of the least and maximum rainfall periods for dry (years ending in 6 or 7) and "wet" years (years ending in 1 or 2). "Wet" years have been classified on the basis of the higher values on the least rainfall periods, mainly with respect to 120 days. Such years therefore should have less deficient rainfall during the drier part of the year, and possibly a better distributed seasonal rainfall.

The apparently cyclic occurrences of particularly deficient rainfall dur-

TABLE 2.-Mean and standard deviation of the least ana maximum rainfall in Fajardo for various time intervals of the year, calculated by decades along a 60-year period (1909-68). The regression coefficient $(\beta)$ and the correlation coefficient $(r)$, obtained when relating the amount of rainfall to the decade number ( 1 to 6$)$, are presented as a measure of the trend in either the least or maximum rainfall periods

\begin{tabular}{|c|c|c|c|c|c|c|c|}
\hline \multirow{2}{*}{$\begin{array}{l}\text { Period and } \\
\text { decade number }\end{array}$} & \multirow{2}{*}{ Measure } & \multicolumn{3}{|c|}{ Least rainfall in- } & \multicolumn{2}{|c|}{ Marimum rainfall in- } & \multirow{2}{*}{$\begin{array}{l}\text { Mean, } \\
\text { annual }\end{array}$} \\
\hline & & 60 days & 120 days & 180 days & 30 days & 90 days & \\
\hline $\begin{array}{c}1909-18 \\
(1) \\
1919-28 \\
(2) \\
1929-38 \\
(3) \\
1939-48 \\
(4) \\
1949-58 \\
(5) \\
1959-68 \\
(6) \\
\text { Mean rainfall } \\
\text { vs. } \\
\text { decade number } \\
60 \text {-year } \\
\text { (1909-1968) }\end{array}$ & $\begin{array}{l}\text { mean } \\
\text { s.d. } \\
\text { mean } \\
\text { s.d. } \\
\text { mean } \\
\text { s.d. } \\
\text { mean } \\
\text { s.d. } \\
\text { mean } \\
\text { s.d. } \\
\text { mean } \\
\text { s.d. } \\
\beta \\
\\
r \\
\text { mean } \\
\text { s.d. }\end{array}$ & $\begin{array}{c}M m . \\
92.2 \\
41.6 \\
93.7 \\
41.6 \\
77.5 \\
32.0 \\
89.9 \\
21.3 \\
77.0 \\
32.3 \\
86.6 \\
32.3 \\
-1.87 \\
\\
0.48 \\
86.2 \\
31.7\end{array}$ & $\begin{array}{c}M m . \\
289.3 \\
79.5 \\
274.3 \\
71.6 \\
234.9 \\
62.5 \\
246.6 \\
75.2 \\
272.5 \\
116.1 \\
225.8 \\
63.2 \\
-8.89 \\
\\
0.66 \\
257.2 \\
80.0\end{array}$ & $\begin{array}{c}M m . \\
533.1 \\
109.5 \\
477.0 \\
86.4 \\
529.8 \\
157.5 \\
518.9 \\
179.6 \\
546.4 \\
185.2 \\
483.1 \\
114.6 \\
-1.50 \\
\\
0.11 \\
514.7 \\
119.9\end{array}$ & $\begin{array}{c}M m . \\
333.2 \\
98.8 \\
336.0 \\
115.1 \\
343.4 \\
91.2 \\
351.0 \\
86.6 \\
332.0 \\
93.5 \\
287.8 \\
75.2 \\
-6.47 \\
\\
0.55 \\
330.4 \\
92.5\end{array}$ & $\begin{array}{l}M m . \\
640.1 \\
175.8 \\
604.8 \\
159.0 \\
654.8 \\
165.1 \\
693.4 \\
119.9 \\
654.3 \\
129.5 \\
586.0 \\
100.1 \\
-2.38 \\
\\
0.11 \\
638.9 \\
142.5\end{array}$ & $\begin{array}{r}\text { Mm. } \\
1633.2 \\
313.9 \\
1543.8 \\
269.0 \\
1748.3 \\
412.5 \\
1605.3 \\
295.1 \\
1625.3 \\
280.4 \\
1429.8 \\
299.5 \\
-21.6 \\
\\
0.43 \\
1597.7 \\
316.7\end{array}$ \\
\hline
\end{tabular}

ing the dry season in years ending in 6 or 7 , or of least deficient rainfall in the dry season with more even seasonal distribution in years ending in 1 or 2 , are not detectable unless the rainfall data is arranged as in tables 1, 2, and 3. When only annual rainfall is considered, or only the maximum rainfall in $\mathbf{3 0}$ or $\mathbf{9 0}$ days, the three parameters do not clearly suggest the apparent existence of the indicated cyclic events (dry and "wet" years). The data presented in table 3 shows that the ratio of mean least rainfall in 120 days (or even in 180 days) of the years ending in 6 or 7 to years ending in 1 or 2 is much smaller than unity, at least when compared with the corre- 


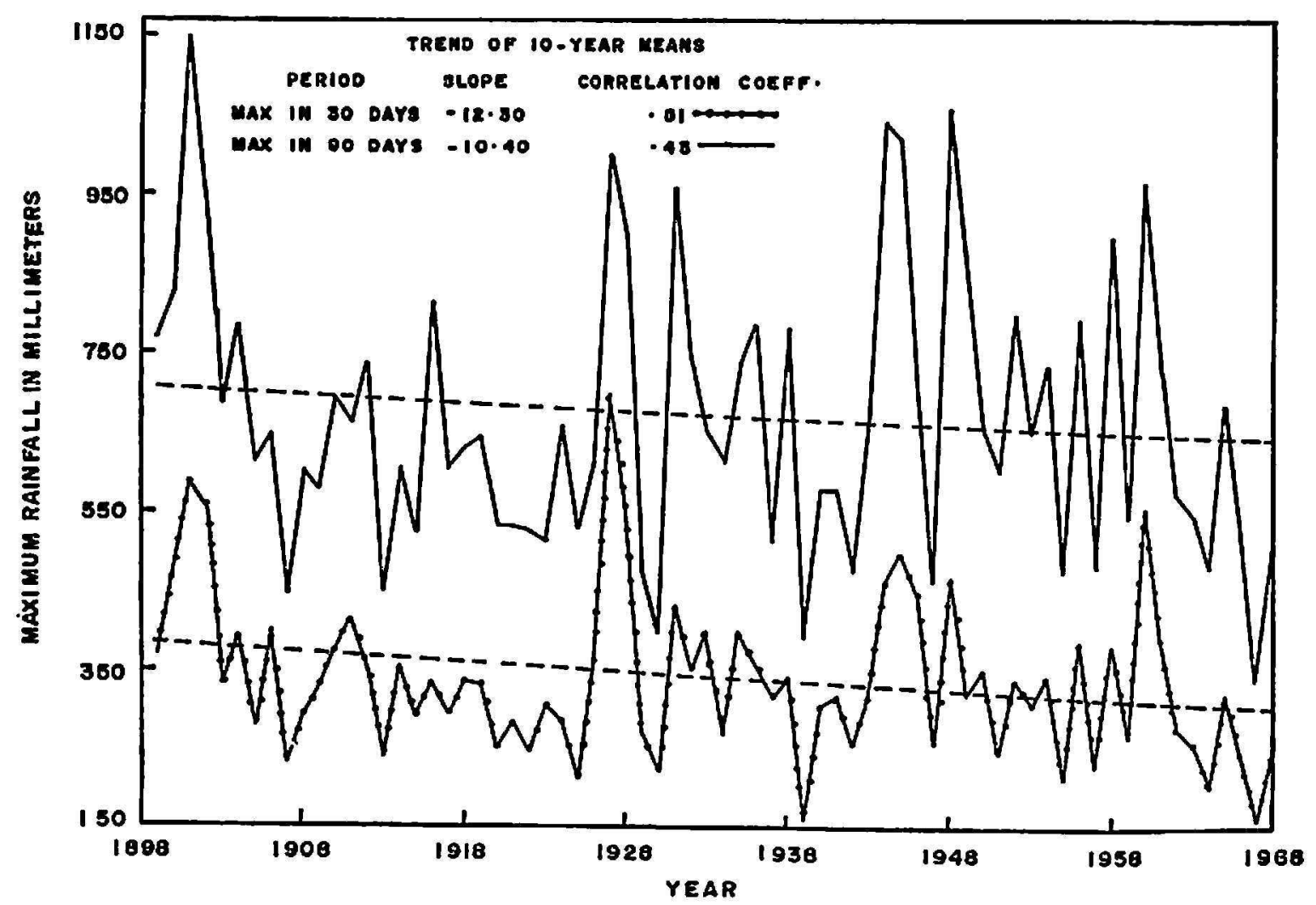

Fia. 3.-Maximum rainfall in 30- and 90-day periods at Caguas during 70 years of daily records. The trend of the maximum rainfall with time, calculated from 10year means of the indicated periods, is shown as to slope and correlation coefficient of the data superimposed over each time-course curve.

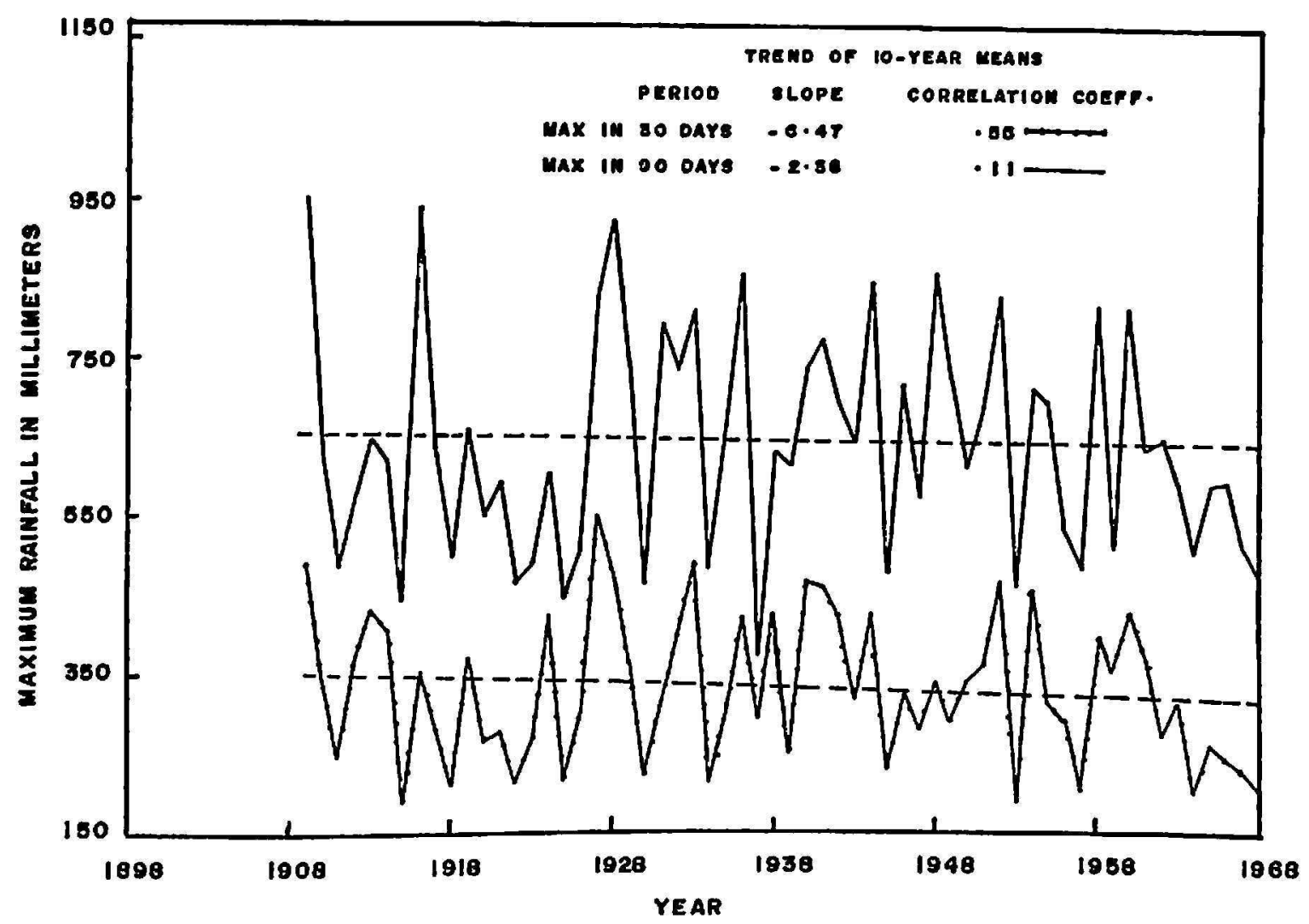

Fia. 4.-Maximum rainfall in 30- and 90 -day periods at Fajardo during 60 years of daily records. The trend of the maximum rainfall with time, calculated from 10 year means of the indicated periods, is shown as to slope and correlation coefficient of the data superimposed over each time-course curve. 
TABLE 3.-Mean and coefficient of variation of the least and maximum rainfall between various time periods of the year, as calculated for "wet" years (ending in 1, or in 2) and for dry years (ending in 6, or in 7). Values are based on 70-and 60-year daily records for Caguas and Fajardo, respectively

\begin{tabular}{|c|c|c|c|c|c|c|}
\hline \multirow{2}{*}{ Rainfall period } & \multicolumn{3}{|c|}{ Least rainfall in- } & \multicolumn{2}{|c|}{$\begin{array}{l}\text { Maximum } \\
\text { rainfall in- }\end{array}$} & \multirow{2}{*}{$\begin{array}{l}\text { Mean, } \\
\text { annual }\end{array}$} \\
\hline & 60 days & 120 days & 180 days & 30 days & 90 days & \\
\hline
\end{tabular}

\section{Caguas}

Mean of "wet" years (in mm.)

Mean of dry years (in mm.)

Mean of $\mathbf{7 0}$ years (in $\mathrm{mm}$.)

Coefficient of variation of "wet" years (percent)

Coefficient of variation of dry years (percent)

Coefficient of variation of all years (percent)

Ratio of mean rainfall in dry to "wet" years

\begin{tabular}{|c|c|c|c|c|c|}
\hline 93.0 & 354.6 & 703.1 & 385.6 & 727.7 & |1873.2 \\
\hline 50.8 & 129.0 & 347.2 & 294.6 & 563.1 & 1250.7 \\
\hline 75.7 & 239.3 & 496.3 & 338.3 & 667.8 & 1579.9 \\
\hline 40.4 & 28.0 & 17.6 & 26.7 & 25.4 & 20.0 \\
\hline 41.0 & 25.6 & 16.0 & 28.8 & 26.1 & 17.6 \\
\hline 42.9 & 36.1 & 29.6 & 30.6 & 27.0 & 20.1 \\
\hline 0.546 & 0.364 & 0.494 & 0.764 & 0.774 & 0.668 \\
\hline \multicolumn{6}{|c|}{ Fajardo } \\
\hline 113.8 & 329.9 & $|698.2|$ & |333.5 & |672.8 & |1930.9 \\
\hline 66.0 & 198.9 & 415.5 & 294.9 & 616.2 & 1472.7 \\
\hline 86.1 & 257.3 & 514.9 & 330.5 & 638.8 & 1597.7 \\
\hline 36.4 & 7.2 & 19.0 & 26.9 & 19.0 & 17.8 \\
\hline 46.9 & 20.4 & 18.9 & 26.2 & 24.0 & 24.4 \\
\hline 36.8 & 31.1 & 23.3 & 28.0 & 22.3 & 19.8 \\
\hline 0.580 & 0.603 & 0.595 & ;) $\quad 0.884$ & 0.916 & 0.763 \\
\hline
\end{tabular}

Mean of "wet" years (in mm.)

Mean of dry years (in mm.)

Mean of 60 years

Coefficient of variation of "wet" years (percent)

Coefficient of variation of dry years (percent)

Coefficient of variation of all years (percent)

Ratio of mean rainfall in dry to "wet" years

sponding ratios of mean annual rainfall or of the maximum rainfall in 30 or in 90 days.

The "wet" years, as previously indicated, not only have the least deficient rainfall in the drier part of the year, but also a more evenly distributed seasonal rainfall as shown in table 3 by further analysis of the data. For example, by calculating the ratio of the minimum rainfall in 180 days to maximum rainfall in $\mathbf{9 0}$ days at Caguas, which should approach 2.00 as an optimum value, it was found that "wet" years compared to all years together have ratios of 0.97 vs. 0.74 . The ratio for dry years is 0.62 ; thus, it can be stated that dry years have an additional characteristic-less eveness in seasonal distribution. The situation at Fajardo is quite similar, although this area exhibits better rainfall distribution (dry, "wet", and all years). 
The rainfall ratio of minimum in $\mathbf{1 8 0}$ days to maximum in 90 days omit only 95 days of the year from consideration. As these days are not among those with most intensive or most deficient rainfall, their effect on reflecting uniformity or lack of uniformity will not add further significance. If in these 95 days, however, the rainfall tends to be either rather excessive or deficient, this fact will be accounted for in the coefficient of mean annual rainfall to annual rainfall of the reference years. This coefficient is proposed later as a component of a rainfall distribution equation.

The suggestion of a cyclic trend in the incidence of rainfall deficiency takes greater support with the finding that the coefficient of variation of the data for dry as well as for "wet" years at either Caguas or Fajardo results in lower values than when analyzing the data for entire 60 - or 70year periods. This normally would not be the case; arbitrarily picking out without basis one out of each 10 years of a given population likely would randomize the data more fully. The coefficient of variation of the least rainfall in 120 days on the dry years (ending in 6 or 7 ) is about 11 percent less at either Caguas or Fajardo than when calculated for all the years (table 3).

Although Fajardo data does not exhibit such a striking difference between dry and "wet" years with respect to the 120-day least rainfall as Caguas data (see the corresponding ratios of dry to wet years shown in table $3-0.603$ vs. 0.364 ), the former area exhibits less variability in the 120-day least rainfall amounts. This is especially true of the "wet" years, the data revealing a coefficient of variation as low as 7.2 percent. The corresponding variation for Caguas ("wet" years) is 28.0 percent. The random occurrence of orographic rainfall in the Caguas area, less likely to occur in Fajardo, is a possible explanation of this difference, more so on "wet" years when unstable conditions prevail more frequently. Caguas and Fajardo otherwise exhibit similar variability in their least and maximum rainfall periods. In general, the longer the rainfall period under consideration the more uniform is its time-course distribution.

Table 4 presents the border dates, at 90 -percent confidence limits, between which the indicated least and maximum rainfall periods are expected to start at Caguas and Fajardo. Both least and maximum rainfall periods are expected to begin within a narrower interval of time at Caguas than at Fajardo. In general, these rainfall periods have similar starting dates in the two areas, especially with respect to the least rainfall in 120 days. Thus, January to April are the driest months at either location, and the period mid-June to mid-September is wettest.

Table 5 is a supplement to table 4 and presented to indicate lower and upper limits of expected rainfall for the periods indicated on table 4. These values were calculated at 90 -percent confidence limits. Caguas and Fajardo 
have similar confidence limits in either the least or maximum rainfall periods.

An evaluation of the skewness in the frequency distribution of the least and maximum rainfall periods at Caguas and Fajardo was made. The coefficient of skewness, $A_{3}$, in which

$$
A_{3}=\left((X-\bar{x})^{3} / S / n\right)
$$

was calculated as a relative measure of assymetry in the frequency distribu-

TABLE 4.-Expected border dates, ${ }^{1}$ at a 90-percent confidence limits, between which the indicaled least and maximum rainfall periods will begin at Caguas and Fajardo

\begin{tabular}{lcccc}
\hline \multicolumn{1}{c}{ Rainfall period } & \multicolumn{2}{c}{ Caguas } & \multicolumn{2}{c}{ Fajardo } \\
\hline & Border dates & Days & Border dales & Days \\
Least rainfall in 60 days & $1 / 29-2 / 14$ & 17 & $2 / 3-2 / 21$ & 18 \\
Least rainfall in 120 days & $12 / 29-1 / 8$ & 11 & $12 / 28-1 / 11$ & 15 \\
Least rainfall in 180 days & $12 / 4-12 / 13$ & 9 & $12 / 9-12 / 25$ & 17 \\
Maximum rainfall in 30 days & $6 / 30-7 / 24$ & 25 & $7 / 2-8 / 6$ & 36 \\
Maximum rainfall in 90 days & $6 / 14-7 / 6$ & 23 & $6 / 19-7 / 12$ & 24 \\
\hline
\end{tabular}

1 November 16 is taken as the first day of each seasonal year.

Table 5.-Lower and upper limits, at 90-percent confidence limits, of expected least and maximum rainfall for the indicated periods at Caguas and Fajardo

\begin{tabular}{|c|c|c|c|c|}
\hline \multirow{2}{*}{ Rainfall period } & \multicolumn{2}{|c|}{ Caguas } & \multicolumn{2}{|c|}{ Fajardo } \\
\hline & Lower limit & Upper limit & Lower limit & Upper limit \\
\hline & $M m$. & $\mathbf{M} m$. & $\Delta I m$. & $M m$. \\
\hline Least rainfall in 60 days & 69.2 & 82.2 & 79.2 & 92.9 \\
\hline Least rainfall in 120 days & 222.0 & 256.5 & 240.0 & 274.5 \\
\hline Least rainfall in 180 days & 467.0 & 525.6 & 489.0 & 540.7 \\
\hline Maximum rainfall in 30 days & 317.7 & 359.0 & 310.0 & 350.4 \\
\hline Maximum rainfall in 90 days & 631.8 & 703.7 & 608.0 & 669.5 \\
\hline Annual rainfall & 1516.5 & 1643.3 & 1534.4 & 1668.5 \\
\hline
\end{tabular}

tion. Table 6 shows the values of $A_{3}$ obtained for the least and maximum rainfall data at both locations. When the values in table 6 were compared with those in the table for testing skewness it was found that the 180day least rainfall distribution of the 70-year Caguas data is symmetric just as the annual rainfall data appears to be. Otherwise, for the rest of the least rainfall data (60- and 120-day) and the maximum rainfall (30and 90-day) positive skewness is confirmed. With respect to Fajardo only the 30- and 90-day maximum rainfall data appear to be symmetric with

Table for testing skewness; G. W. Snedecor and W. G. Cockram, table A-6, Statistical Methods, Iowa State Univ. Press, 6th ed., p. 552, 1969. 
respect to the mean. For the least rainfall (60-, 120-, and 180-day) distribution as well as the annual rainfall distribution positive skewness also is confirmed. Thus, while in the Caguas area, only the least rainfall in 180 days follows a normal distribution, as well as the annual rainfall; only the maximum rainfall in 30- and 90-day periods in Fajardo follow a normal distribution, although the annual rainfall has a skewed distribution.

\section{RAINFALL DISTRIBUTION}

As one measure of the irregularity in rainfall distribution during the year, a condition likely to contribute to drought seriousness, a rainfall distribution coefficient $(D I S)$ was developed from the organized rainfall data. This may be calculated by the proposed equation

$$
D I S=\frac{\text { maximum rainfall in } 90 \text { days } \times \text { mean annual rainfall }}{\text { least rainfall in } 180 \text { days } \times \text { annual rainfall of reference year }}
$$

Table 6.-Skewness in the distribution around the mean of the least and maximum rainfall poriods studied for Caguas and Fajardo

\begin{tabular}{|c|c|c|}
\hline \multirow{2}{*}{ Rainfall period } & \multicolumn{2}{|c|}{ Coefficient of skewness, $A^{2}$} \\
\hline & Caguas & Fajardo \\
\hline Least rainfall in 60 days & $0.631^{*}$ & $0.570^{*}$ \\
\hline Least rainfall in 120 days & $0.886^{*}$ & $.589 *$ \\
\hline Least rainfall in 180 days & 0.448 & $.682^{*}$ \\
\hline Maximum rainfall in 30 days & $1.024^{*}$ & .285 \\
\hline Maximum rainfall in 90 days & $0.637^{*}$ & .335 \\
\hline Annual rainfall & 0.432 & $.797^{*}$ \\
\hline
\end{tabular}

* Confirmations of positive skewness.

Equation 1 should approach 0.50 from higher values, as it may be deducted directly from the cquation. The calculated values of DIS at both Caguas and Fajardo ranged from 3.08 to 0.61 . The ratio of the maximum rainfall in 90 days to the least rainfall in 180 days involves nearly three-fourths of the year as there is no overlap between the two parameters (see table 4). The ratio of the mean annual to the actual annual rainfall of the year being considered accounts for its year-round rainfall deficiency relative to a long term annual mean. Thus, if the annual rainfall of a given year is well below average, say two-thirds of the annual mean, and even if this scarce rainfall is uniformly distributed along the year, DIS will still increase 50 percent above the approached optimum of 0.50 . In other words, equation 1 involves deficiency or excess in annual rainfall with the unevenness in rainfall distribution along the given year. In doing so the contribution of the ground water reserves relative to an average year is roughly accounted for. 
Although the data of the least rainfall in 120 days at Caguas, rather than that in 180 days, appears to suggest the existence of a cyclic trend with greater clarity, the latter figure was used to calculate DIS because the equation then includes a greater portion of the year, although dry periods can well extend to 6 months, especially on the leeward side of the Cordillera.

\section{RAINFALL DEFICIENCY}

Rainfall deficiency is another characteristic as significant to agricultural needs, if not more so, than distribution. A Rainfall Deficiency Index ( $D E F)$, based on the regression of accumulated rainfall on accumulated time, is proposed in the equation

$$
D E F=\beta-25.4\left(1-r^{2}\right)-10 S_{\beta}
$$

where $\beta$ and $S_{\beta}$ represent the regression coefficient (precipitation rate per day) and the standard error associated with $\beta$, respectively. The term $1-r^{2}$ is introduced to account for the deviations about the regression of accumulated rainfall with time. Likewise, the term $10 S_{\beta}$, besides contributing further to correct for the deviations about regression, appears to incorporate additional distribution characteristics of the annual rainfall into equation 2. At Caguas, the term $10 S_{\beta}$ made up 15 of 74 percent that $D E F$ accounts for DIS. At Fajardo, the inclusion of this term increased the correspondence between $D I S$ and $D E F$ by 10 percent. The variations in $r^{2}$ and $S_{\beta}$ do not appear to correspond in full with each other, adding to 68 and 61 percent for Caguas and Fajardo respectively. Thus, it is believed that $S_{\beta}$ also takes into account that generally the rainfall increases at a greater rate during the second half of the year (May to November) than during the first half (November to May); at least more than $r^{2}$. This is reflected mostly on the value of the intercept, forced to deviate from the origin toward negative values, as May to November rainfall becomes more intense. It was found that fluctuations in $S_{\beta}$ account for fluctuations in the intercept, 30 and 26 percent more than what $r^{2}$ accounts for, at Caguas and Fajardo, respectively.

$\beta$, on the other hand, is essentially a deficiency measure as long as $r^{2}$ and $S_{\beta}$ are high and low, respectively. This is why $\beta$ needs correction, as in 1936 and 1948. The latter year, one of the few dry years not ending in either 6 or 7 , resulted with a $\beta$ value of 5.156. If the annual rainfall of nearly 2,020 $\mathrm{mm}$. during 1948 would have been evenly distributed, the $D E F$ could have approached the actual $\beta$ value for that year. Poor distribution is illustrated by the least rainfall in 180 consecutive days being barely $396 \mathrm{~mm}$. or 19.6 percent of the annual rainfall. Although the least rainfall in 180 days is not involved in equation $2, D E F$ in 1948 is equal to -0.686 , one of the 5 lowest recorded in the 70-year period. It was during this year that Calvesbert (2) obtained the lowest Palmer's Drought Index (PDI) during a 35-year per- 
iod for the eastern interior of Puerto Rico. The PDI value obtained is -4.26 , which means severe drought conditions in Palmer's classification. However, it would be difficult to realize that the year 1948, with an annual rainfall well above average $(2,020 \mathrm{~mm}$.) would experience considerable rainfall deficiency.

\section{TIME-COURSE OF DIS AND DEF AND THE SUGGESTED CYCLES}

Tables 7 and 8 present the mean and standard deviation of $D I S$ and $D E F$, averaged by decades, for Caguas and Fajardo, respectively. The corresponding values of the indices for the suggested "wet" and dry years are also indicated below each decade. To evaluate both indices on the two tables more objectively it should be remembered that $D I S$ approaches 0.5 from greater values as the rainfall becomes more evenly distributed during the year at the time the annual rainfall approaches the longterm mean.

On the other hand, $D E F$ should approximate 5.0 (or slightly more) from lesser values as the rainfall meets but does not exceed optimum evaporative demands. An excess of rainfall during any season of the year is adequately accounted for by equation 2 , as mentioned previously. This is justified, not only from the natural soil drainage point of view, but also because heavy rainfall leads to reduced solar energy and high air humidity, both of which are adverse environmental conditions for optimum plant growth. The assumption is made that, starting with soil moisture at or near field capacity, successive increments of about $50 \mathrm{~mm}$. of rainfall per 10-day periods can largely prevent an appreciable plant-water deficit, or at the opposite extreme impose a drainage problem. This assumption is relatively safe because the year starts November 16 for the purpose of this study, when the soil should be amply recharged with moisture from the preceeding heavy rainfall during October and early November.

The time-course of $D E F$ exhibits a normal distribution at Caguas and Fajardo when evaluated by the coefficient of skewness, $A_{3}$. DIS, however, was found to be distributed assymetrically at either location. $D E F$ also has the advantage over $D I S$ in pin-pointing the rainfall deficiency by years and locations on an equal basis.

With previous considerations as noted, tables 7 and 8 can be evaluated more effectively as to the time-course (by decades) of $D I S$ and $D E F$, the former stressing the distribution picture, the latter the deficiency aspect, both indices integrating ingredients of the two characteristics. No general trend is apparent toward unfavorable rainfall conditions at either Caguas or Fajardo in meeting agricultural needs. There appears to be a tendency, however, for a steady decrease with time of the least rainfall in 120 days at Caguas. The regression of decade means (first 5 decades) and medians (last 
TABLE 7.-Mean and standard deviation (s.d.) of the Rainfall Distribution Coefficient (DIS) and of the Rainfall Deficiency Index (DEF), averaged by decades and for the 70-year period covered in the Caguas data. The corresponding values for the dry and "wet" year on each decade as well as the mean value of all dry and "wet" years are also included

\begin{tabular}{|c|c|c|c|c|}
\hline \multirow{2}{*}{ Period } & \multicolumn{2}{|c|}{ DIS } & \multicolumn{2}{|c|}{$D E F$} \\
\hline & Mean & S.d. & Mean & S.d. \\
\hline $1899-1908$ & 1.35 & 0.47 & 1.432 & 1.245 \\
\hline “Wet" year (1902) & 0.67 & & 3.886 & \\
\hline Dry year (1906) & 1.90 & & 0.483 & \\
\hline $1909-1918$ & 1.43 & .48 & 1.321 & 1.270 \\
\hline “Wet" year (1911) & 0.86 & & 2.819 & \\
\hline Dry year (1916) & 1.86 & & -1.143 & \\
\hline $1919-1928$ & 1.38 & .41 & 1.262 & 1.321 \\
\hline "Wet" year (1921) & 0.83 & & 2.845 & \\
\hline Dry year (1926) & 2.38 & & -1.270 & \\
\hline 1929-1938 & 1.46 & .62 & 1.610 & 0.991 \\
\hline "Wet" year (1931) & 0.92 & & 2.845 & \\
\hline Dry year (1936) & 2.38 & & -0.051 & \\
\hline $1939-1948$ & 1.61 & .82 & 1.321 & 1.372 \\
\hline "Wet" year (1942) & 0.96 & & 2.438 & \\
\hline Dry year (1948) & 2.08 & & -0.686 & \\
\hline 1939 (Dry) & 3.08 & & -0.584 & \\
\hline 1944 (Dry) & 2.92 & & -0.203 & \\
\hline 1949-1958 & 1.57 & .64 & 1.168 & 1.676 \\
\hline "Wet" year (1952) & 0.93 & & 2.311 & \\
\hline Dry year (1957) & 1.98 & & -0.152 & \\
\hline $1959-1968$ & 1.62 & .77 & 1.204 & 1.499 \\
\hline "Wet" year (1962) & 1.01 & & 2.819 & \\
\hline Dry year (1967) & 2.17 & & 0.660 & \\
\hline $1899-1968$ & 1.49 & .60 & 1.332 & 1.306 \\
\hline "Wet" years & 0.88 & .11 & 2.852 & 0.506 \\
\hline Dry years & 2.11 & .21 & -0.308 & 0.755 \\
\hline
\end{tabular}

2 decades) of this parameter on the decade number reflects a highly significant $\left(r^{2}=.96\right)$ decrease of the 120-day least rainfall during the 70 years of record at Caguas. The standard deviation of data in tables 7 and 8 , especially the former, however, is too high to conclude any definite trend. The decade values suggest more definitely that conditions for rainfall deficiency exist for Caguas; somewhat more than for Fajardo 
TABLE 8.-Mean and standard deviation (s.d.) of the Rainfall Distribution Coefficient (DIS) and of the Rainfall Deficiency Index (DEF), averaged by decades and for the 60-year period covered by the Fajardo data. The corresponding values for the dry and "wel" year in each decade, as well as the mean value of all "wel" and dry years, are also indicated

\begin{tabular}{|c|c|c|c|c|}
\hline \multirow{2}{*}{ Period } & \multicolumn{2}{|c|}{ DIS } & \multicolumn{2}{|c|}{$D E F$} \\
\hline & Mean & S.d. & Mean & S.d. \\
\hline $1909-1918$ & 1.22 & 0.31 & 1.440 & 1.549 \\
\hline "Wet" year (1911) & 0.91 & & 2.870 & \\
\hline Dry year (1916) & 1.37 & & -0.432 & \\
\hline $1919-1928$ & 1.34 & .28 & 1.572 & 1.118 \\
\hline "Wet" year (1921) & 0.96 & & 2.769 & \\
\hline Dry year (1926) & 1.68 & & 0.127 & \\
\hline 1929-1938 & 1.24 & .43 & 1.547 & 1.092 \\
\hline "Wet" year (1931) & 0.73 & & 3.226 & \\
\hline Dry year (1936) & 1.20 & & 0.965 & \\
\hline 1939-1948 & 1.56 & .69 & 1.608 & 1.397 \\
\hline "Wet year (1942) & 0.61 & & 4.039 & \\
\hline Dry year (1948) & 2.21 & & -0.102 & \\
\hline 1939 (Dry) & 2.11 & & 0.356 & \\
\hline 1944 (Dry) & 2.72 & & -0.051 & \\
\hline 1949-1958 & 1.32 & .51 & 1.687 & 1.735 \\
\hline "Wet" year (1952) & 0.73 & & 3.531 & \\
\hline Dry year (1957) & 1.43 & & 0.686 & \\
\hline $1959-1968$ & 1.45 & .49 & 1.613 & 0.660 \\
\hline "Wet" year (1062) & 0.99 & & 2.565 & \\
\hline Dry year (1967) & 2.50 & & 1.194 & \\
\hline $1909-1968$ & 1.36 & .45 & 1.578 & 1.245 \\
\hline "Wet" years & 0.82 & .15 & 3.166 & 0.549 \\
\hline Dry years & 1.73 & .51 & 0.406 & 0.641 \\
\hline
\end{tabular}

(see $D E F$ values). Such deficiencies can be accounted for mostly by poor distribution (see $D I S$ values).

The suggestion of a cyclic occurrence of "wet" and dry years, on the basis of the least rainfall data tabulated in table 3, is supported by the $D I S$ and $D E F$ indices summarized in tables 7 and 8 for Caguas and Gurabo. As suggested by the 120- and 180-day least rainfall data, Caguas and Fajardo again exhibit sharp differences in $D I S$ and $D E F$ when comparing these indices for years ending in 1 or 2 or 6 or 7. The Caguas data (table 7 ) is again, more revealing. The mean differences in $D E F$ between dry and 
"wet" years during the 7 decades in the Caguas area is 237 percent greater than the mean $D E F$ for the 70 -year data (3.160 vs. 1.332$)$. At the same time, the mean standard deviation of the "wet" and dry years is 48.2 percent of the standard deviation for all years. In Fajardo, the mean difference in $D E F$ between dry and "wet years" $(2.760)$ is 175 percent greater than the mean $D E F$ for the 60-year data (1.578). The mean standard deviation of the "wet" and the dry years is 47.8 percent of the standard deviation of $D E F$ for the 60 years. It also is interesting to note that the standard deviation of the $D E F$ index for dry, "wet", and all years is similar for both Caguas and Fajardo.

The DIS index is also consistent with the possible existence of dry and "wet" years, especially as applied to Caguas. Here, the mean difference in DIS between dry and "wet" years (1.23) is 83 percent of the mean DIS during the 70 years (1.49). The mean standard deviation of dry and "wet" years is only 26.7 percent of the mean standard deviation for the 70-year period. At Fajardo, DIS exhibits less contrast between dry and "wet" years with respect to all the years. The mean difference between dry and "wet" years is 67 percent of that for all years ( 0.91 vs. 1.36$)$, while the standard deviation is not much less for the cyclic years than for all the years (73 percent).

The meteorologic answer to the observed occurrence of "wet" and dry years at regular intervals is beyond the scope of this paper. The only reported phenomenon known to the authors, which might give origin to the suggested cycles, are the sun spots. Such spots are said to migrate around the sun and in-line with the earth and the sun twice in each cycle. Depending on the exact effect of the spots, years of less deficient rainfall during the dry season, accompanied by better annual distribution (years ending in 1 or 2), and years of critically deficient rainfall followed by less even annual distribution (years ending in 6 or 7 ) which alternate about every 5 years, can perhaps be tied in with the phenomenon. However, the development of an index that can be used to integrate rainfall deficiency and distribution for allocating the most of this natural resource to agricultural planning-has been accomplished. $D E F$ might furnish the characterization more adequately that $D I S$, particularly in areas where the annual rainfall is not normally distributed, as at Fajardo (table 6). DIS is basically a relative index, applicable for comparative purposes to areas with similar annual rainfall.

$D E F$ is an index that considers in greater depth the time-course characteristics of annual rainfall in terms of deficiency and distribution. When comparing the annual values of $D E F$ at Caguas with the least rainfall in 180 days, it was found to account for nearly 70 percent of the fluctuations in the period, slightly less than that which $D I S$ accounts for although the 
latter index incorporates such terms in its equation. $D E F$ also is better related to the least rainfall in $\mathbf{1 2 0}$ days at either location.

\section{SUMMARY}

A statistical evaluation was made of the daily rainfall at Caguas and Fajardo, covering 70 - and 60 -year periods. The purposes of this evaluation were: 1 , To investigate the character, if any, of the rainfall distribution and of its deficiency (drought) characteristics; and 2, in the event that any character was found in rainfall in the sense of distribution and deficiency, to develop a Rainfall Deficiency Index which would be useful to agricultural and other programs and inventories.

The study first consisted of determining the least rainfall in 60,120 , and 180 consecutive days, and the maximum rainfall in 30 and 90-day periods of each year. This analysis suggested the occurrence of most deficient and least deficient rainfall in 120 (or 180) day cycles during the drier part of the year within 10- to 11-year periods; the Caguas data beginning in 1899 and in 1909 at Fajardo. The suggested cycles appear to be more defined at Caguas than Fajardo. It appears that years ending in 6 or 7 almost invariably seemed to be among the driest in their respective decades; 1899 to 1968. Years ending in 1 or 2 seemed identified with least deficient and better distributed rainfall. This preliminary analysis was based mainly on the least rainfall in 120 days parameter.

It was found that the ratio of the mean least rainfall in 120 days of the dry years (ending in 6 or 7 ) to the "wet" years (ending in 1 or 2) is 0.364 for Caguas and 0.603 for Fajardo. Also, the coefficient of variation of the data for dry and "wet" years was lower than when calculated for all years. Contrast between dry and wet years is apparent even for the least rainfall in 180 days (6 months of the year). In this respect the ratios of dry to "wet" years are 0.494 and 0.595 for Caguas and Fajardo, respectively. There is no apparent contrast, however, when the annual, or even maximum, rainfall in 90 days at the two locations is compared for "wet" and dry years.

A Rainfall Deficiency Index $(D E F)$ is proposed. Such deficiency is normally distributed for Caguas and Fajardo. This index integrates the deficiency and distribution characteristics of the annual rainfall. It can be used, therefore, as a guide for evaluating the rainfall characteristics in the agricultural regions of Puerto Rico and for the determination of priorities for supplemental irrigation.

A Rainfall Distribution Coefficient (DIS) was developed as a direct means of describing the distribution characteristics of annual rainfall, and it accounts indirectly for the rainfall deficiency within a given area or areas of similar annual rainfall. $D E F$ accounted for 74.0 and 64.4 percent of the variations in DIS at both Caguas and Fajardo. 


\section{RESUMEN}

Se evaluaron estadísticamente los datos diarios sobre la lluvia en Caguas y Fajardo durante 70 y 60 años, respectivamente. Los objetivos principales de la evaluación fueron: 1, Investigar el patrón de distribución anual de la lluvia, si es que existe y 2, de ser asf, desarrollar entonces un Indice de Deficiencia de Lluvia (DEF), que pueda ser útil para la planificación agrícola de Puerto Rico.

El primer paso fue determinar para ambas áreas (Caguas y Fajardo) la cantidad mínima de lluvia durante periodos de 60,120 y 180 días consecutivos, así como la máxima durante 30 y 90 días, en cada uno de los años comprendidos en el estudio. Este análisis de por sí sugiere que durante la temporada de sequía tiene lugar una incidencia cíclica de lluvia particularmente deficiente, que coincide con los años que terminan en 6 6 7. Así mismo se observó que en ciclos de 10 a 11 años la lluvia es generalmente menos deficiente durante la temporada de sequía en aquellos años que terminan en 162 . En relación con este hecho, el coeficiente de lluvia mínima en 120 días de los años más secos (los que terminan en 66 7) respecto al de los menos secos (los que terminan en 162 ) es 0.364 para Caguas y 0.603 para Fajardo. El contraste, por tanto, es más evidente en el caso de Caguas. Los coeficientes de variabilidad de los respectivos datos, tanto para los años secos como para los menos secos, resultan más bajos que cuando el cálculo se hace para todos los años.

Para caracterizar la distribución y la deficiencia de la lluvia anualmente se propone un Indice de Deficiencia (DEF), que permite hacer una determinación numérica. Este índice puede ser útil para fines de comparaciones hídricas entre áreas y establecer asl prioridades respecto al suministro de riego suplementario.

\section{LITERATURE CITED}

1. Bogart, D. B., Arnold, T., and Crooks, J. W., Water Resources of Puerto Rico, U. S. Geological Survey, Water Resources Bull. No. 4, 1964.

2. Calvesbert, R. J., Climatological of Meteorological Drought in Puerto Rico, Proceedings, Conference on Climatology and Related Fields in the Caribbean, Mona, Jamaica, 1966.

3. Mode, E. B., Elements of Statistics, Prentice-Hall, Inc., Englewood Cliffs, N. J., 2d ed., 377 pp., 1951.

4. Picó, R., Geografía de Puerto Rico, Parte I, Editorial Universitaria, Río Piedras, P. R., 1954 .

5. Weather Bureau, Climatological Data, Puerto Rico and Virgin Islands, Monthly Weather Summary.

6. Weather Bureau, Climatological Data, Puerto Rico and Virgin Islands, Annual Summary.

7. Weather Bureau, Generalized Estimates of Probable Maximum Precipitation and Rainfall Frequency Data for Puerto Rico and Virgin Islands, Technical Paper No. 42, 1961.

8. Weather Bureau, Decennial Census of the U. S. Climate. Monthly Normals of Temperature and Precipitation, Puerto Rico and Virgin Islands, Climatography of the U. S. No. 81-45, 1962.

9. Weather Bureau, Decennial Census of the U. S. Climate, Climatic Summary of Puerto Rico and Virgin Islands, Climatography of the U. S. No. 86-45, 1965. 